\title{
Is There A Difference Between Domestic And Foreign Risk Premium? The Case Of China Stock Market
}

\author{
Frédéric Teulon, IPAG Business School, France \\ Khaled Guesmi, IPAG Business School \& University of Paris, France \\ Salma Fattoum, INSEEC Business School - Lyon, France
}

\begin{abstract}
This article studies the dynamic return and market price of risk for Chinese stocks (A-B shares). A Multivariate DCC-GARCH model is used to capture the feature of time-varying volatility in stock returns. We show evidence of different pricing mechanisms explained by the difference in the expected return and market price of risk between $A$ and $B$ shares. However, the significance of the difference between market prices of risk disappears if GARCH models are used.
\end{abstract}

Keywords: Asymmetric DCC-GARCH Models; B-Share Discount; Chinese Stock Market; Market Segmentation

\section{INTRODUCTION}

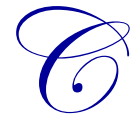

hina has gradually opened to foreign investment since the early $1990 \mathrm{~s}$. We present a model relating to the Shanghai Stock Exchange (SHSE). One peculiarity of this stock market is that two main classes of stock are traded: B-shares are quoted in U.S. dollar, and they are open to foreign investment; A-shares are quoted in yuan, and are only available to domestic investors. This situation allows foreign investors to pay a much lower price than domestic ones.

Such variation in investment possibilities across stocks naturally gives an ideal setting in evaluating the impact of foreign investment restrictions (Bailey, 1994; Bailey et al., 1999). Previous research on foreign investment restriction demonstrates that these kinds of barriers have substantial effects on stock prices (Eun \& Janakiramanan, 1986; Hietala, 1989).

Bailey (1994) is one of the first to notice this issue and he concludes that this foreign price discount can be explained by the correlation between (B) shares returns available for foreign investors and have price discount (compared to A shares, which are only available for domestic investors) and international stock market. Chen, Lee, and Rui (2001), Chui and Kwok (1998), and Yang (2003) investigate the information held by domestic and foreign investors and state that the B-share discount is due to information asymmetry between segmented investors, however, these papers fail to reach agreement on which investors, foreign ones or domestic ones, are better informed. Tan et al. (2008) consider on their side that no asymmetry is apparent in the B-share market. Karolyi and Li (2003) conclude that B-share discount is closely related to market capitalization and substantial past-return momentum but unrelated to the firm's risk and liquidity attributes. Chan et al. (2008) examine the effect of information asymmetry on equity prices in the local A- and foreign B-shares markets. More recently, Mei et al. (2009) attribute the puzzle to the different speculative motives between different investors by empirical analysis.

None of the aforementioned models has studied the dynamics of stock prices in continuous time for Chinese stock market. Nevertheless, the stock prices are assumed to follow Geometric Brownian Motion (GBM) by adopting different forms for drift and volatility terms resources. The literature so far has analyzed this phenomenon mainly by looking at the co-movements between stocks. We estimate the constant drift and volatility then decompose the drift term into risk-free rate and market price of risk multiplying volatility. The market price of risk 
is assumed to be constant and time independent. The couples of the corresponding A and B share stock returns are first assumed to follow Bivariate Normal Distribution and in order to capture the time-varying property of volatility, Multivariate GARCH model with Dynamic Conditional Correlation is used to estimate the volatility term and test is re-done based on GARCH model.

Our paper contributes to the published literature in three ways. First, we offer a model to understand the effects of multiple class of equity that differentiate between foreign and domestic investors. Second, we demonstrate that despite lower liquidity, the B stock market is much more volatile. Third, the results provide additional support to the hypothesis of different demand elasticity's between foreign and domestic investors.

The paper is organized as follows. Section 2 describes the model. We present the data in Section 3. Results are reported and discussed in Section 4 and we conclude in Section 5.

\section{THE MODEL}

The pricing deviation between A and B shares arises from the fact that almost all B shares are priced at a great discount compared to the corresponding A shares. We define the market-value weighted B share discount at time $t$ from the dynamics of both shares; satisfy the following Stochastic Differential Equations:

$$
\begin{aligned}
& d S_{A t}=\left(r_{f, A t}+{ }_{A}{ }_{A}\right) S_{A t} d t+{ }_{A} S_{A t} d W_{A t} \\
& d S_{B t}=\left(r_{f, B t}+{ }_{B}{ }_{B}\right) S_{B t} d t+{ }_{B} S_{B t} d W_{B t} \\
& d W_{A t} d W_{B t}=d t
\end{aligned}
$$

Shares A and B are issued by the same company. The AB-share has the same voting rights and the same dividend, yet A and B shares are held by different investors and priced differently. $S_{A t}$ and $S_{B t}$ are the prices of respective $\mathrm{A}$ and $\mathrm{B}$ shares, $r_{f, A t}$ and $r_{f, B t}$ are the domestic and foreign risk free rate at time $\mathrm{t}$ and $\lambda_{A}$ and $\lambda_{B}$ are the corresponding domestic and foreign market price of risk or market price of risk. $W_{A t}$ and $W_{B t}$ are the corresponding Wiener process for A and B shares, and $\rho$ is the correlation coefficient between them.

In order to estimate the parameters, we adopt the Maximum Likelihood Estimation (QMLE) process. From Equation (1) we know that the log price pair follows the Bivariate Normal Distribution:

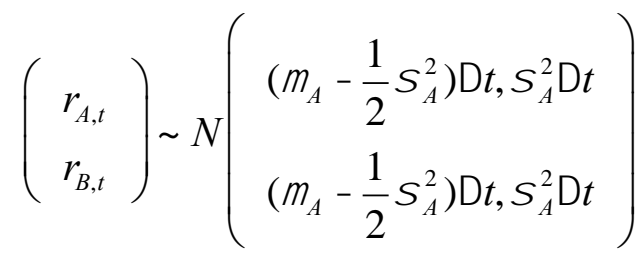

with

$r_{A, t}=\log S_{A, t} \quad \log S_{A, t} \quad$

$r_{B, t}=\log S_{B, t} \log S_{B, t} \quad t$

Then the joint density function for $r_{A, t}, r_{B, t}$ is: 


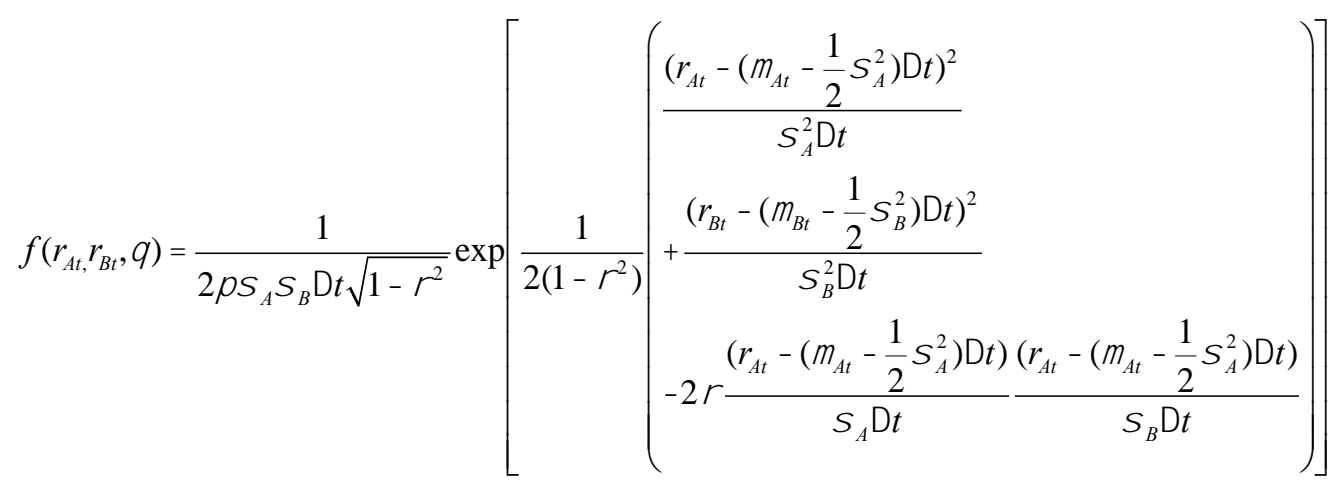

And is the parameter vector:

$$
=\left({ }_{A},{ }_{B},{ }_{A},{ }_{B}, \quad\right)
$$

The conditional $\log$ likelihood of $r_{A, t}, r_{B, t}$ is therefore:

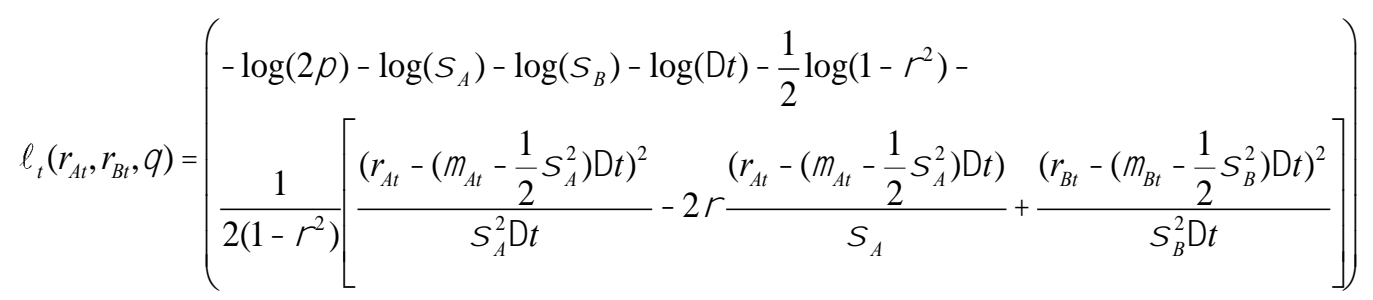

The log likelihood of the whole data series is:

$$
L\left(r_{A 1}, r_{B 1}, \ldots, r_{A T}, r_{B T} ;\right)={ }_{t=1}^{T} \ell_{t}\left(r_{A t}, r_{B t} ;\right)
$$

We consider the time-varying case for both drift and volatility terms. We consider the A-B share pairs; actually we only need the bivariate version of the model. Take a couple of A-B shares returns $\left(\mathbf{r}_{t}\right)$, we apply the time-varying correlation coefficients estimated from a multivariate DCC-GARCH model intruded by Engle (2002).

By allowing conditional correlations to vary over time, his specification is viewed as a generalization of the Constant Conditional Correlation model (CCC model, Bollerslev, 1990). To illustrate the dynamic conditional correlation model for our purposes, let $x_{t}$ be a $(2 \times 1)$ vector containing the return, volume, and implied volatility series in a conditional mean equation as:

$$
\mathbf{r}_{t}={ }_{t}+{ }_{t}
$$

where $\mu_{t}=E\left[x_{t} \| \Pi_{t-1}\right]$ is the conditional expectation of $x_{t}$ given the past information $\Pi_{t-1}$, and $\varepsilon_{t}$ is a vector of errors in the auto regression $\mathrm{AR}(1)$, are assumed to be conditional multivariate normally distributed, with means of zero and variance-covariance matrix $H_{\mathbf{t}} \equiv\left\{h_{i j}\right\}$. Under the assumption that the return, volume, and implied volatility series $x_{t}$ are determined by the information set available at time $\mathrm{t}-1$, the model may be estimated using maximum likelihood methods, subject to the requirement that the conditional covariance matrix, $H_{\mathbf{t}}$, be positive 
definite for all values of $\boldsymbol{\varepsilon}_{\mathbf{t}}$ in the sample. We also assume that $\mu_{\mathrm{t}}$ has the following formation as:

$\mu_{i, t}=\Phi_{0}+\Phi_{1} x_{i, t-1}, \forall \mathrm{i}$

$\Phi_{1}$ measures the ARCH effect in data series. In the traditional multivariate GARCH framework, the conditional variance-covariance matrix can be written as:

$$
\begin{aligned}
& H_{t}=D_{t} R_{t} D_{t} \\
& D_{t}=\operatorname{diag}\left(\sqrt{h_{11, t}}, \sqrt{h_{22, t}}\right) \\
& R_{t}=\left(\begin{array}{lll}
1 & 1 & 2
\end{array}\right) R+{ }_{1} t_{t 1}+{ }_{2} R_{t} \text { with }{ }_{1}+{ }_{2}<0
\end{aligned}
$$

$H_{t}$ is the variance-covariance matrix of returns at time $t . R_{t}$ is the $(2 \times 2)$ symmetric matrix of dynamic conditional correlations. $D_{t}$ is a diagonal matrix of conditional standard deviations for each of the return series, obtained from estimating a univariate GJR-GARCH ${ }^{1}$ process in the equation of variance expressed as:

$$
h_{i i, t}=w_{i}+\alpha_{i} \varepsilon_{i i, t-1}^{2}+\beta_{i} h_{i i, t-1}+\gamma_{i} I_{i, t} \varepsilon_{i i, t-1}^{2}
$$

where persistence is measured by the coefficients $\quad{ }_{i}$ and the indicator variables $\mathrm{I}_{\mathrm{i}, \mathrm{t}}$ captures asymmetry in the estimate of coefficients ${ }_{i}$. A negative value of ${ }_{i}$ implies that negative residuals increase the variance more than positive residuals excess returns.

\section{THE DATA}

The data is collected from Datastream International and there are 18 companies, ${ }^{2}$ which have both listed A, and B monthly shares which are continuously traded during the sample period, which runs from the beginning of 1997 to the June of 2008. It excludes episodes of the recent international financial crisis that could generate biased estimates. Except for three companies in the services sector, most firms in the sample belong to the industrial sector: textiles, chemicals, consumer goods, mechanical, building materials, or tires. The 3-month deposit rate in China is adopted as a proxy for the risk-free rate. For the risk-free U.S. dollar rate, the 3-month U.S. Treasury note rate is used. Also notice that A shares are traded in Chinese Yuan, but B shares are traded in U.S. dollar. In order to calculate returns in a consistent way, first we need to adjust A and B share prices into the Chinese Yuan.

\section{RESULTS AND DISCUSSION}

\section{Estimation of Market Price of Risk}

Table 1 presents the estimation result of the market price of risk and volatility term for Equation (1). From this table, we can see several features of these estimated parameters.

First, we notice that almost all the drift terms of B shares are larger than those of the corresponding A shares. We can underline that the expected returns of B shares are larger than those of A shares, as the model suggests.

Secondly, our results demonstrate that the annual volatility for all B shares are higher A shares. This result

\footnotetext{
${ }^{1}$ This Model gives better statistical results than DCC-GARCH. Results are witnessed by the AIC and BIC criteria.

${ }^{2}$ This restriction allows us to avoid the numerical convergence problem when the number of companies is above 18 . In practice, we have attempted to estimate our model with different numbers of companies, but the specification with 18 companies does not face converge problem and provides best fit to the data as witnessed by the AIC, BIC, and Log-likelihood criteria.
} 
seems to be contradictory with previous studies. For example, some papers argue that B share market is less liquid than A share market and thus investors require liquidity premium in order to compensate for B shares, this partly contributes to the B share pricing puzzle. Since B shares are less liquid than A shares it is reasonable to assume that the volatility of B shares is also less than the corresponding A shares. However this is not the case in our estimation. The result tells us that although most B shares have less trading volume than A shares yet they have higher volatility. One reason for this is that may be the ratio of institutional investors in B shares is higher than in A shares, so it is easier for them to manipulate the B shares price and thus makes the price more volatile. Another reason which can also contribute to this issue is that in 2001 the policy for the B share investment restriction has been released and B share price fluctuates more frequently than A share around that time, this also increases the volatility (Bohl et al., 2009).

We agree with Stulz and Wasserfallen (1995) and Domowitz et al. (1997) to say that there is a bias: The fact that investors prefer local stocks to foreign equities led to an imbalance in the demand and prices between different classes of shares. Our results give additional support for Stulz and Wasserfallen (1995) hypothesis that companies discriminate between investor groups which have different demand elasticities.

Overall, as non-residents have the opportunity to invest in shares listed overseas or in Hong Kong, if they wish to take stakes in Chinese companies, the segment B remains largely neglected.

Table 1: Market Price of Risk Estimation - 1997/2008

\begin{tabular}{|c|c|c|c|c|c|c|}
\hline & \multicolumn{2}{|c|}{ A-share } & \multicolumn{2}{|c|}{ B-share } & \multirow{2}{*}{$\lambda_{\mathrm{B}}-\lambda_{\mathrm{A}}$} & \multirow[b]{2}{*}{$\sigma_{\mathrm{B}}-\sigma_{\mathrm{A}}$} \\
\hline & $\lambda_{A}$ & $\sigma_{A}$ & $\lambda_{B}$ & $\sigma_{B}$ & & \\
\hline Shanghai Refrigerator \& Compressor & 0.055 & 0.560 & 0.199 & 0.789 & $\begin{array}{c}0,144 \\
(2.0763)^{* * *}\end{array}$ & $\begin{array}{c}0,229 \\
(2.28)^{* * *}\end{array}$ \\
\hline Jinqiao Export \& Import & -0.111 & 0.286 & 0.142 & 0.359 & $\begin{array}{c}0,253 \\
(3.2983)^{* * *}\end{array}$ & $\begin{array}{c}0,073 \\
2.033)^{* *}\end{array}$ \\
\hline Outer Gaoqiao & -0.189 & 0.371 & 0.197 & 0.436 & $\begin{array}{c}0,386 \\
(3.4194)^{* * *}\end{array}$ & $\begin{array}{c}0,065 \\
(1.743)^{*}\end{array}$ \\
\hline JinJiang Investment & 0.147 & 0.433 & 0.367 & 0.478 & $\begin{array}{c}0,22 \\
2.7611)^{* * *}\end{array}$ & $\begin{array}{c}0,045 \\
2.678)^{* *}\end{array}$ \\
\hline Forever Bicycle & 0.216 & 0.433 & 0.897 & 0.590 & $\begin{array}{c}0,681 \\
(1.750)\end{array}$ & $\begin{array}{c}0,157 \\
2.678)^{* *}\end{array}$ \\
\hline Phoenix Bicycle & 0.567 & 0.278 & 0.645 & 0.289 & $\begin{array}{c}0,078 \\
3.345)^{* * *}\end{array}$ & $\begin{array}{c}0,011 \\
(0.334)\end{array}$ \\
\hline Shanghai Haixing Group & 0.897 & 0.391 & 0.989 & 0.478 & $\begin{array}{c}0,092 \\
(1.221)\end{array}$ & $\begin{array}{c}0,087 \\
(1.087)\end{array}$ \\
\hline Yaohua Pilkington Glass & 0.678 & 0.286 & 0.823 & 0.378 & $\begin{array}{c}0,145 \\
(2.50)^{* * *}\end{array}$ & $\begin{array}{l}0,092 \\
(1.21)\end{array}$ \\
\hline Shanghai Diesel Engine & 0.111 & 0.145 & 0.786 & 0.678 & $\begin{array}{c}0,675 \\
(2.678)^{* * *}\end{array}$ & $\begin{array}{c}0,533 \\
(2.999)^{* * *}\end{array}$ \\
\hline Shanghai Vacuum Electronics & 0.381 & 0.289 & 0.386 & 0.571 & $\begin{array}{c}0,005 \\
(1.925)\end{array}$ & $\begin{array}{c}0,282 \\
(0.321)\end{array}$ \\
\hline Shanghai Erfangji & 0.145 & 0.478 & 0.298 & 0.576 & $\begin{array}{c}0,153 \\
(1.4951)\end{array}$ & $\begin{array}{c}0,098 \\
(1.734)^{*}\end{array}$ \\
\hline Dazhong Taxi & 0.071 & 0.214 & 0.349 & 0.324 & $\begin{array}{c}0,278 \\
(4.146)^{* * *}\end{array}$ & $\begin{array}{c}0,11 \\
(3.987)^{* * * *}\end{array}$ \\
\hline Yongsheng Stationery & 0.129 & 0.456 & 0.189 & 0.675 & $\begin{array}{c}0,06 \\
(0.901)\end{array}$ & $\begin{array}{c}0,219 \\
(0.111)\end{array}$ \\
\hline China First Pencil & 0.012 & 0.102 & 0.121 & 0.203 & $\begin{array}{c}0,109 \\
(0.900)\end{array}$ & $\begin{array}{c}0,101 \\
(2.236)^{* * * *}\end{array}$ \\
\hline China Textile Machinery & 0.675 & 0.236 & 0.817 & 0.338 & $\begin{array}{c}0,142 \\
(0.6034)\end{array}$ & $\begin{array}{c}0,102 \\
(1.458)\end{array}$ \\
\hline Shanghai Rubber Belt & 0.237 & 0.138 & 0.363 & 0.278 & $\begin{array}{c}0,126 \\
(1.578)\end{array}$ & $\begin{array}{c}0,14 \\
(0.933)\end{array}$ \\
\hline Shanghai Chlor-Alkali Chemicals & 0.003 & 0.278 & 0.1450 & 0.488 & $\begin{array}{c}0,142 \\
(1.641)^{*}\end{array}$ & $\begin{array}{c}0,21 \\
(1.962)^{* *}\end{array}$ \\
\hline Shanghai Tire \& Rubber & 0.001 & 0.311 & 0.278 & 0.686 & $\begin{array}{c}0,277 \\
(1.3769) \\
\end{array}$ & $\begin{array}{c}0,375 \\
(1.986)^{* *}\end{array}$ \\
\hline
\end{tabular}


Note. $\mathrm{H}_{0}: \lambda_{B}-\lambda_{A}=0, \sigma_{B}-\sigma_{A}=0$, the values within brackets are the t-statistics. ***, **, and $*$ indicates significance at better than the $1 \%, 5 \%$, and $10 \%$ levels, respectively.

\section{Market Price of Risk with Dynamic Volatility}

The results for the market price of risk estimations are presented in the Table 2 . Note that most of the estimation of market price of risk becomes much smaller to their corresponding parts in Table 1. This is not a surprise because we can imagine that most of the fluctuations in the return series have been absorbed by timevarying volatility parts. The most interesting thing for us is that the difference of market price of risk between A and B shares becomes insignificant for all stocks, we show higher market price of risk for B shares. However if we adopt GARCH-DCC model to do the same work, then property of higher B share market price of risk largely disappears for individual twin shares. Thus it is safe to say that the seemingly higher market price of risk for B shares is caused by the incapability of the model to capture the time-varying feature of volatility, when models are used to correct the heteroscedasticity in volatilities, this property disappears.

Table 2: Market Price of Risk Estimation Under DCC GARCH Model - 1997/2008

\begin{tabular}{|c|c|c|c|}
\hline & A-share & B-share & \\
\hline & $\lambda_{A}$ & $\lambda_{B}$ & $\lambda_{B}-\lambda_{A}$ \\
\hline Shanghai Refrigerator \& Compressor & -0.004 & 0.010 & $\begin{array}{c}-0.014 \\
(0.224)\end{array}$ \\
\hline Jinqiao Export \& Import & -0.012 & -0.001 & $\begin{array}{c}-0.011 \\
(0.897)\end{array}$ \\
\hline Outer Gaoqiao & -0.062 & -0.031 & $\begin{array}{c}-0.031 \\
(0.045)\end{array}$ \\
\hline JinJiang Investment & -0.013 & -0.054 & $\begin{array}{c}0.041 \\
(0.056)\end{array}$ \\
\hline Forever Bicycle & -0.015 & -0.020 & $\begin{array}{c}0.005 \\
(0.089)\end{array}$ \\
\hline Phoenix Bicycle & -0.006 & 0.007 & $\begin{array}{c}-0.013 \\
(0.755)\end{array}$ \\
\hline Shanghai Haixing Group & -0.002 & -0.004 & $\begin{array}{c}0.002 \\
(0.012)\end{array}$ \\
\hline Yaohua Pilkington Glass & -0.023 & -0.007 & $\begin{array}{c}-0.016 \\
(0.011)\end{array}$ \\
\hline Shanghai Diesel Engine & -0.038 & -0.006 & $\begin{array}{c}-0.032 \\
(0.089)\end{array}$ \\
\hline Shanghai Vacuum Electronics & -0.007 & 0.002 & $\begin{array}{c}-0.009 \\
(0.786)\end{array}$ \\
\hline Shanghai Erfangji & -0.025 & -0.011 & $\begin{array}{c}-0.014 \\
(0.754)\end{array}$ \\
\hline Dazhong Taxi & -0.028 & -0.021 & $\begin{array}{l}-0.007 \\
(0.453)\end{array}$ \\
\hline Yongsheng Stationery & -0.002 & 0.010 & $\begin{array}{c}-0.012 \\
(0.564)\end{array}$ \\
\hline China First Pencil & -0.007 & 0.016 & $\begin{array}{c}-0.023 \\
(0.786)\end{array}$ \\
\hline China Textile Machinery & -0.007 & 0.458 & $\begin{array}{c}-0.465 \\
(0.786)\end{array}$ \\
\hline Shanghai Rubber Belt & -0.016 & -0.017 & $\begin{array}{c}0.001 \\
(0.789)\end{array}$ \\
\hline Shanghai Chlor-Alkali Chemicals & -0.008 & -0.006 & $\begin{array}{c}-0.002 \\
(0.897)\end{array}$ \\
\hline Shanghai Tire \& Rubber & -0.014 & 0.004 & $\begin{array}{c}-0.018 \\
(0.452)\end{array}$ \\
\hline
\end{tabular}

Note. $\mathrm{H}_{0}: \lambda_{B}-\lambda_{A}=0$, the values within brackets are the t-statistics.

\section{CONCLUSION}

In this paper, we consider the behavior of the corresponding Chinese stock price. We have investigated the 
price and the volatility for the A-B shares of 18 companies quoted at the Shanghai Stock Exchange.

The B shares are priced at a significant discount compared to the corresponding A shares. B shares have higher expected returns than A shares. The empirical test is consistent with the model for both markets. Moreover, the higher B share expected returns not only come from the higher risk-free rate and higher volatility, the market price of risk of $\mathrm{B}$ shares is also higher than the corresponding A shares. The market price of risk estimation shows that individual B shares investors hold higher market price of risk than A share investors. Besides, the averaged difference for market price of risk is still positive and significant. The GARCH-DCC estimation shows that the difference between the market price of risk of A and B shares is very close to zero and the t-statistics are quite insignificant. This means that the estimation result of higher market price of risk is largely caused by the heteroskedasticity of volatility, such property of higher market price of risk disappears when a suitable dynamic volatility model, is implemented.

\section{AUTHOR INFORMATION}

Frédéric Teulon, Ph.D., Department of Finance, IPAG Lab, IPAG Business School, 184 Bd Saint Germain, 75006 Paris, France. E-mail: f.teulon@ipag.fr

Khaled Guesmi, Ph.D., Department of Finance, IPAG Lab, IPAG Business School, France and EconomiX - CNRS (UMR 7235), University of Paris Ouest Nanterre La Defense, France. E-mail: khaled.guesmi@ipag.fr

Salma Fattoum, Ph.D., INSEEC Business School - Lyon, France. E-mail: sfattoum@inseec.com (Corresponding author)

\section{REFERENCES}

1. Bailey, W. (1994). Risk and return on China's new stock markets: Some preliminary evidence. Pacific Basin Finance Journal, 2, 243-260.

2. Bailey, W., Chung, Y. P., \& Kang, J. (1999). Foreign ownership restrictions and equity price premiums: What drives the demand for cross-border investments? Journal of Financial and Quantitative Analysis, 34(4), 489-512.

3. Bohl, M., Schuppli, M., \& Siklos, P. (2009). Stock return seasonalities and investor structure: Evidence from China's B-share markets. (BOFIT Discussion Papers 20).

4. Bollerslev, T. (1990). Modeling the coherence in short-run nominal exchange rates: A multivariate generalized ARCH approach. Review of Economics and Statistics, 72, 498-505.

5. Chan, K., Menkveld, A., \& Yang, Z. (2008). Information asymmetry and asset prices: Evidence from the China foreign share discount. Journal of Finance, 63, 159-196.

6. Chen, G. M., Lee, B.-S., \& Rui, O. (2001). Foreign ownership restrictions and market segmentation in China's stock markets. The Journal of Financial Research, 24, 133-155.

7. Chui, A., \& Kwok, C. (1998). Cross-autocorrelation between A shares and B shares in the Chinese stock market. The Journal of Financial Research, 21, 333-353.

8. Domowitz, I., Glen, J., \& Madhavan, A. (1997). Market segmentation and stock prices: Evidence from an emerging market. Journal of Finance, 52(3), 1059-1086.

9. Engle, R. E. (2002). Dynamic conditional correlation: A Simple class of multivariate generalized autoregressive conditional heteroscedasticity models. Journal of Business and Economic Statistics, 20, 339350.

10. Eun, C., \& Janakiramanan, S. (1986). A model of international asset pricing with a constraint on the foreign equity ownership. Journal of Finance, 41, 1015-1024.

11. Hietala, P. (1989). Asset pricing in partially segmented markets: Evidence from the Finnish markets. Journal of Finance, 44, 697-718.

12. Karolyi, A., \& Li., L. (2003). A resolution of the Chinese discount puzzle. (Working Paper). Ohio State University.

13. Mei, J., Scheinkman, J., \& Xiong, W. (2009). Speculative trading and stock prices: Evidence from Chinese A-B share premia. Annals of Economics and Finance, 10, 225-255. 
14. Stulz, R. M., \& Wasserfallen, W. (1995). Foreign Equity investment restrictions and shareholder wealth maximization: Theory and evidence. Review of Financial Studies, 8, 1019-1058.

15. Tan, L., Chiang, T., Mason, J., \& Nelling, E. (2008). Herding behavior in Chinese stock markets: An examination of A and B shares. Pacific Basin Finance Journal, 16(1-2), 61-77.

16. Yang, J. (2003). Market segmentation and information asymmetry in Chinese stock markets: A VAR analysis. The Financial Review, 38, 591-609. 